\title{
Factors associated with adverse outcomes from cardiovascular events in the kidney transplant population: an analysis of national discharge data, hospital characteristics, and process measures
}

\author{
Amit K. Mathur ${ }^{1,2^{*}}$ (D) Yu-Hui Chang ${ }^{2}$, D. Eric Steidley ${ }^{3}$, Raymond L. Heilman ${ }^{4}$, Nabil Wasif ${ }^{1,2}$, David Etzioni ${ }^{1,2}$, \\ Kunam S. Reddy ${ }^{1}$ and Adyr A. Moss ${ }^{1}$
}

\begin{abstract}
Background: Kidney transplant (KT) patients presenting with cardiovascular (CVD) events are being managed increasingly in non-transplant facilities. We aimed to identify drivers of mortality and costs, including transplant hospital status.

Methods: Data from the 2009-2011 Nationwide Inpatient Sample, the American Hospital Association, and Hospital Compare were used to evaluate post-KT patients hospitalized for MI, CHF, stroke, cardiac arrest, dysrhythmia, and malignant hypertension. We used generalized estimating equations to identify clinical, structural, and process factors associated with risk-adjusted mortality and high cost hospitalization $(\mathrm{HCH})$.

Results: Data on 7803 admissions were abstracted from 275 hospitals. Transplant hospitals had lower crude mortality (3.0\% vs. 3.8\%, $p=0.06$ ), and higher un-adjusted total episodic costs (Median $\$ 33,271$ vs. $\$ 28,022, p<$ 0.0001). After risk-adjusting for clinical, structural, and process factors, mortality predictors included: age, CVD burden, CV destination hospital, diagnostic cardiac catheterization without intervention (all, $p<0.001$ ). Female sex, race, documented co-morbidities, and hospital teaching status were protective (all, $p<0.05$ ). Transplant and nontransplant hospitals had similar risk-adjusted mortality. $\mathrm{HCH}$ was associated with: age, CVD burden, CV procedures, and staffing patterns. Hospitalizations at transplant facilities had 37\% lower risk-adjusted odds of HCH. Cardiovascular process measures were not associated with adverse outcomes.
\end{abstract}

Conclusion: KT patients presenting with CVD events had similar risk-adjusted mortality at transplant and nontransplant hospitals, but high cost care was less likely in transplant hospitals. Transplant hospitals may provide better value in cardiovascular care for transplant patients. These data have significant implications for patients, transplant and non-transplant providers, and payers.

Keywords: Cardiovascular disease, Care delivery, Economics, Kidney transplant

\footnotetext{
* Correspondence: Mathur.amit@mayo.edu

'Division of Transplant Surgery, Department of Surgeyr, Mayo Clinic Arizona,

5777 East Mayo Boulevard, Phoenix, AZ 85054, USA

${ }^{2}$ Robert D. and Patricia E. Kern Center for the Science of Health Care Delivery,

Mayo Clinic, Phoenix, AZ, USA

Full list of author information is available at the end of the article
}

(c) The Author(s). 2019 Open Access This article is distributed under the terms of the Creative Commons Attribution 4.0 International License (http://creativecommons.org/licenses/by/4.0/), which permits unrestricted use, distribution, and reproduction in any medium, provided you give appropriate credit to the original author(s) and the source, provide a link to the Creative Commons license, and indicate if changes were made. The Creative Commons Public Domain Dedication waiver (http://creativecommons.org/publicdomain/zero/1.0/) applies to the data made available in this article, unless otherwise stated. 


\section{Background}

Cardiovascular events are the leading cause of death after kidney transplantation (KT). Significant amounts of research have been aimed at reducing event rates, primarily aimed at understanding prevalent risk factors, defining outcomes, and application of guideline-based care [1-4]. Event rates continue to be high and endanger long-term patient and transplant outcomes.

Post-KT cardiovascular event are among the most important drivers of post-kidney transplant health care utilization and mortality [5]. KT recipients have high rates of hospitalization for myocardial infarction (MI), congestive heart failure (CHF), dysrhythmias, stroke (CVA), malignant hypertension, and cardiac arrest. Mortality is as high as to $20 \%$ in some hospitals. Few studies have focused on the rescue of KT patients once these events occur [6]. Patient and hospital factors may contribute to adverse outcomes from CVD events. Hospitals are known to vary in cardiac care practices [7-11], and structural features including teaching status, technology, and staffing patterns are associated with better outcomes [12]. KT patients bring an even greater challenge in this setting - rescue from an acute cardiovascular event requires facility resources and well-developed care processes, which can be leveraged from transplant programs. The presence of these resources may improve outcomes and reduce costs of cardiovascular care, but this idea remains unexplored.

In this analysis, we aimed to understand how hospitals perform in the management of cardiovascular disease in kidney transplant patients. We modeled hospital characteristics including structural factors and cardiovascular process measures as well as clinical factors to identify predictors of inpatient mortality and costs [13]. We hypothesized that transplant hospitals $(\mathrm{TH})$ would have lower mortality and costs compared to non-transplant hospitals $(\mathrm{NTH})$, after adjustment for their inherent characteristics and patient differences.

\section{Methods}

\section{Conceptual model}

Figure 1 displays a conceptual model of factors that affect outcomes when kidney transplant recipients have cardiovascular events. We considered patient-level and hospital-level factors (structure and processes of care) that could affect outcomes in this population. In this context, resource intensity - the presence of specialty cardiac services, intensive care, teaching status, nurse staffing and other factors - would be associated with favorable outcomes, after adjusting for patient differences.

\section{Data sources}

Using data from the Nationwide Inpatient Sample (NIS), the American Hospital Associatation (AHA) Annual
Survey of Hospitals, and Hospital Compare we created a novel dataset capturing admissions from kidney transplant patients admitted with cardiovascular events based on specific diagnoses, merged with hospital resource characteristics and cardiovascular process measures from 2009 to 2011, as previously described [6, 14]. The Nationwide Inpatient Sample (NIS) is a $20 \%$ deidentified national administrative data sample of all U.S. hospital discharges which contains hospital episodebased patient demographics, clinical diagnoses and treatments based on 9th International Classification of Disease (ICD-9) codes. The American Hospital Association (AHA) Annual Survey of Hospitals provided hospital structural characteristics using the Medicare provider number. Survey data includes 1000 data elements on organizational structure, facilities, payer mix, and financial performance from 6500 U.S. hospitals. Structural domains included in the model included TH status, hospital finances, inpatient and cardiovascular care capacity, staffing patterns and teaching status. Cardiovascular process metrics and outcomes are published by the Centers for Medicare and Medicaid Services on the Hospital Compare website (http://www.medicare.gov/hospitalcompare), and were merged by Medicare provider number. The metrics used included time to ECG on arrival, incidence of aspirin on arrival to ED for MI, proportion of MI patients receiving fibrinolytic therapy within $30 \mathrm{~min}$, and time to transfer to another facility for acute coronary intervention. Hospital outcome metrics included baseline rates of inpatient 30-day mortality and readmission for $\mathrm{MI}$ and $\mathrm{CHF}$.

To create the final study population, kidney transplant patients (V42.0, kidney transplant status) who were admitted with at least one primary or secondary cardiovascular diagnosis were isolated. Cardiovascular diagnoses included: myocardial infarction (MI) (410.x), congestive heart failure (CHF) (428.x), dysrhythmia (427.x), cerebrovascular accident (CVA) (436.x, 437.1, 997.x), malignant hypertension (402.x), and cardiac arrest (427.5, 997.1). Multi-organ transplants were omitted. The final models were limited to patients with functioning allografts by restricting the dataset to those records without billing codes for inpatient dialysis use (14.2\%), which are most relevant to transplant quality metrics. The final dataset was restricted to hospitals with greater than 10 admissions. Clinical risk-adjustment was based on the presence diabetes mellitus and the Charlson comorbidity score. Hospital cost-to-charge ratios provided by the Centers for Medicare and Medicaid Services were used to to determine episodic costs, as described previously [15]. The GDP Implicit Price Deflator was used to adjust for inflation, centered on 2011 dollars [16].

Patient socio-demographics and clinical data, facility structural characteristics, process measures, and baseline 


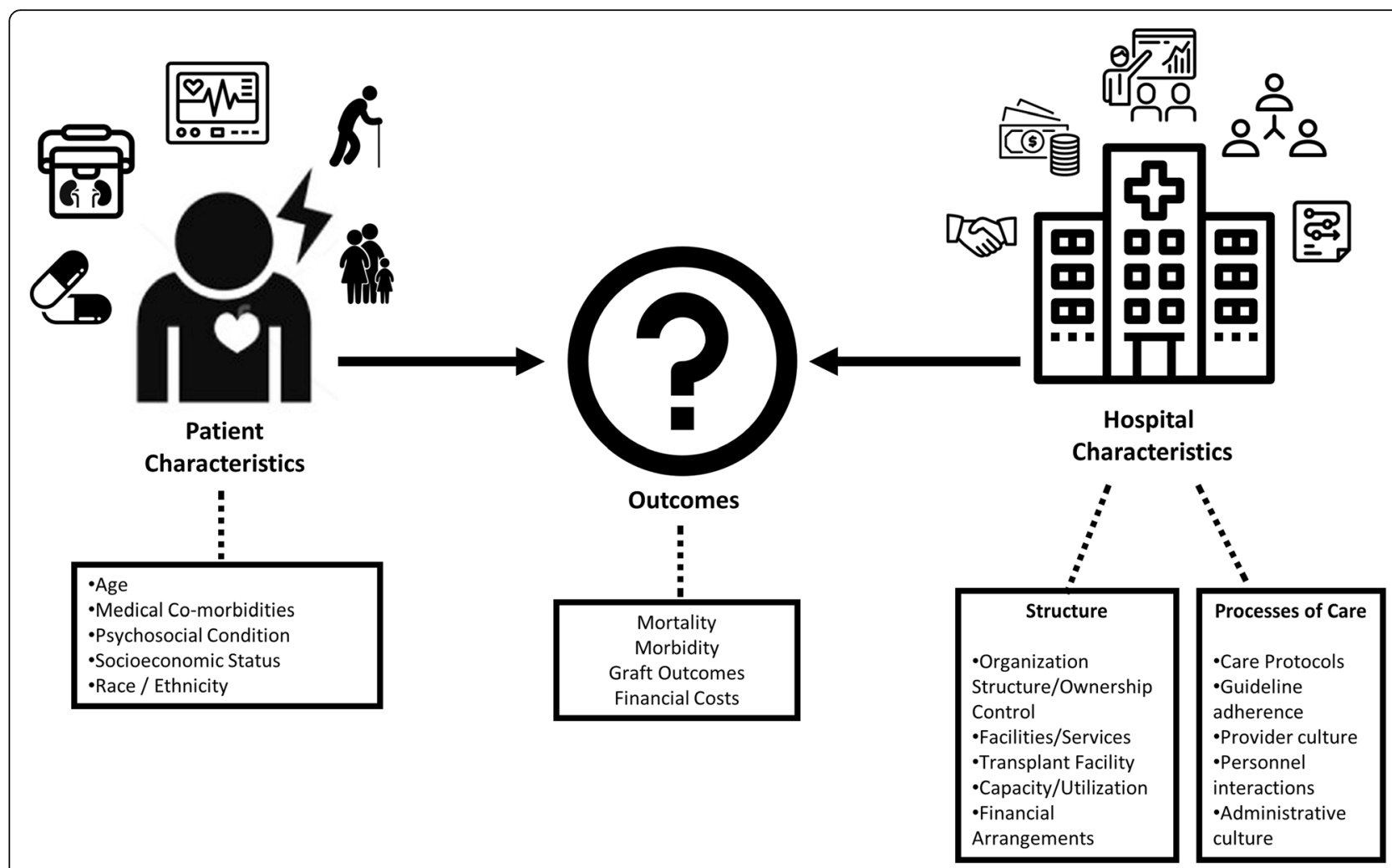

Fig. 1 Drivers of Clinical and Financial Outcomes for Kidney Transplant Patients Admitted for Inpatient Care for Cardiovascular Events. This conceptual model encapsulates the factors that contribute to outcomes when a kidney transplant recipient is admitted for inpatient care for a cardiovascular event. Kidney transplant patients admitted to hospitals with cardiovascular dysfunction are a complex population. They require multi-disciplinary coordinated care, multiple levels of acute inpatient care, comprehensive nephrology and cardiology services, specialized imaging and therapeutic capabilities, and other resources to address deterioration of kidney function, threatened allografts, immunosuppression, and numerous other queries. Well-resourced hospitals may be better equipped to prevent adverse outcomes when cardiovascular events occur in this population. Our analysis employed multi-level statistical models based on the Donabedian model of health care quality, with riskadjustment for 1) patient characteristics, 2) key facility structural factors, which include organizational elements, facilities and services, as well as ownership and financial status, and 3) processes of care that appropriately utilize facilities and services to deliver treatment. Based on this structure, we hypothesized that transplant hospitals would have better clinical and financial outcomes than non-transplant hospitals from cardiovascular events in the kidney transplant population

hospital cardiovascular performance metrics (in nontransplant patients) used in final models are displayed in Table 1. Facility characteristics such as total hospital expenses (which are expressed in the AHA dataset in US dollars) and total inpatient days, were ranked and divided into quartiles for presentation.

\section{Statistical analysis \\ Determinants of mortality}

We constructed generalized estimating equations (GEE) to identify factors associated with mortality [17], while accounting for patient clustering by hospital, as individual hospitals possess unique structural and process characteristics that could affect all patients within their cluster. Structural and process of care variables were included to address clustering. The Classification and Regression Tree (CART) method to identify relevant hospital variables associated with mortality and hospital transplant status for multivariate analysis [18]. The CART method optimizes the classification of observations into mutually exclusive groups in a non-parametric approach. The method identifies a single variable able to strongly divide observations into two groups. The observations are further sub-divided within groups using the same method in an iterative process, until pre-specified stopping rules are met.

GEE estimates were used to construct the odds ratio (OR) and the 95\% CI for individual covariates, after applying backward elimination techniques to select the best model (retained variables had $p$-value $<0.4$ ). The quasi-likelihood under independence model criterion (QIC) was used to measure model fitness, and compared across three models: the model with transplant status only, the model with transplant status and patient characteristics, and the model with transplant status, patient and hospital characteristics [19]. Similar to the Akaike's 
Table 1 Differences in Demographic, Clinical, and Facility Characteristics among Kidney Transplant Patients Admitted with Cardiovascular Disease, by Transplant Hospital Status

\begin{tabular}{|c|c|c|c|c|}
\hline \multicolumn{5}{|l|}{ Demographic and Clinical Characteristics } \\
\hline & $\begin{array}{l}\text { Non-transplant Hospital } \\
(n=197)\end{array}$ & $\begin{array}{l}\text { Transplant Hospital } \\
(n=78)\end{array}$ & $\begin{array}{l}\text { Total } \\
(n=275)\end{array}$ & $p$-value \\
\hline Hospitalizations $(n, \%)$ & $3893,49.9 \%$ & $3910,50.1 \%$ & & \\
\hline Year of admission & & & & $<0.001$ \\
\hline 2009 & $1182(30.4 \%)$ & $1349(34.5 \%)$ & $2531(32.4 \%)$ & \\
\hline 2010 & $1238(31.8 \%)$ & 1155 (29.5\%) & $2393(30.7 \%)$ & \\
\hline 2011 & $1473(37.8 \%)$ & $1406(36.0 \%)$ & 2879 (36.9\%) & \\
\hline Age, Median (Q1, Q3) & $64(55.0,70.0)$ & $62(53.0,69.0)$ & $63(54.0,70.0)$ & $<0.001$ \\
\hline Female & $1484(38.1 \%)$ & $1453(37.2 \%)$ & $2937(37.6 \%)$ & 0.37 \\
\hline Race, White & $2337(64.4 \%)$ & 2109 (57.4\%) & $4446(60.9 \%)$ & $<0.001$ \\
\hline \multicolumn{5}{|l|}{ Cardiovascular Diagnosis } \\
\hline MI (410.x) & $383(9.8 \%)$ & $305(7.8 \%)$ & $688(8.8 \%)$ & 0.002 \\
\hline Stroke (997.x/436/437.1) & $247(6.3 \%)$ & $461(11.8 \%)$ & $708(9.1 \%)$ & $<0.001$ \\
\hline CHF (428.x) & $2110(54.2 \%)$ & 1968 (50.3\%) & $4078(52.3 \%)$ & $<0.001$ \\
\hline Dysrhythmia (427.x) & $2138(54.9 \%)$ & $2027(51.8 \%)$ & 4165 (53.4\%) & 0.006 \\
\hline Cardiac arrest (427.5/997.1) & $85(2.2 \%)$ & $102(2.6 \%)$ & $187(2.4 \%)$ & 0.22 \\
\hline Malignant HTN (402.x) & $59(1.5 \%)$ & $85(2.2 \%)$ & $144(1.8 \%)$ & 0.03 \\
\hline Number of CV diagnosis & & & & 0.02 \\
\hline 1 & $2902(74.5 \%)$ & 3005 (76.9\%) & 5907 (75.7\%) & \\
\hline$\geq 2$ & $991(25.5 \%)$ & $905(23.1 \%)$ & $1896(24.3 \%)$ & \\
\hline Weighted Charlson score & & & & $<0.001$ \\
\hline 0 & $467(12.0 \%)$ & $828(21.2 \%)$ & $1295(16.6 \%)$ & \\
\hline 1 & $471(12.1 \%)$ & $754(19.3 \%)$ & 1225 (15.7\%) & \\
\hline 2 & $1158(29.7 \%)$ & $1102(28.2 \%)$ & 2260 (29.0\%) & \\
\hline $3+$ & $1797(46.2 \%)$ & $1226(31.4 \%)$ & 3023 (38.7\%) & \\
\hline Diabetes mellitus & 2012 (51.7\%) & 1959 (50.1\%) & 3971 (50.9\%) & 0.16 \\
\hline Dialysis use in hospital & $749(19.2 \%)$ & $356(9.1 \%)$ & 1105 (14.2\%) & $<0.001$ \\
\hline Admission type & & & & $<0.001$ \\
\hline Emergent/Urgent & $2884(88.3 \%)$ & 2850 (83.1\%) & $5734(85.6 \%)$ & \\
\hline Elective/Others & $383(11.7 \%)$ & $581(16.9 \%)$ & $964(14.4 \%)$ & \\
\hline Transferred in indicator & $302(7.8 \%)$ & $509(13.0 \%)$ & $811(10.4 \%)$ & $<0.001$ \\
\hline Cardiovascular Procedure (catheter-based or cardiac surgery) & $757(19.5 \%)$ & $772(19.7 \%)$ & $1529(19.6 \%)$ & 0.74 \\
\hline Died in hospital & $146(3.8 \%)$ & $117(3.0 \%)$ & $263(3.4 \%)$ & 0.06 \\
\hline \multicolumn{5}{|l|}{ Facility Structural Characteristics } \\
\hline Hospital Type & & & & 0.09 \\
\hline Government, nonfederal & $14(7.1 \%)$ & $12(15.4 \%)$ & $26(9.5 \%)$ & \\
\hline Non-profit, non-gov't & $175(88.8 \%)$ & $62(79.5 \%)$ & $237(86.2 \%)$ & \\
\hline Investor-owned & $8(4.1 \%)$ & $4(5.1 \%)$ & $12(4.4 \%)$ & \\
\hline Medical/surgical intensive care & $191(97.0 \%)$ & $78(100.0 \%)$ & $269(97.8 \%)$ & 0.12 \\
\hline Cardiac intensive care & $141(71.6 \%)$ & $71(91.0 \%)$ & $212(77.1 \%)$ & $<0.001$ \\
\hline HMO hospital & $17(8.6 \%)$ & $9(11.5 \%)$ & $26(9.5 \%)$ & 0.46 \\
\hline PPO hospital & $16(8.1 \%)$ & $3(3.8 \%)$ & $19(6.9 \%)$ & 0.21 \\
\hline Specialty cardiology \& cardiac surgery services & $186(94.4 \%)$ & $77(98.7 \%)$ & $263(95.6 \%)$ & 0.12 \\
\hline Freestanding/Satellite ED hospital & $25(12.7 \%)$ & $6(7.7 \%)$ & $31(11.3 \%)$ & 0.24 \\
\hline
\end{tabular}


Table 1 Differences in Demographic, Clinical, and Facility Characteristics among Kidney Transplant Patients Admitted with Cardiovascular Disease, by Transplant Hospital Status (Continued)

\begin{tabular}{|c|c|c|c|c|}
\hline \multicolumn{5}{|l|}{ Demographic and Clinical Characteristics } \\
\hline & $\begin{array}{l}\text { Non-transplant Hospital } \\
(n=197)\end{array}$ & $\begin{array}{l}\text { Transplant Hospital } \\
(n=78)\end{array}$ & $\begin{array}{l}\text { Total } \\
(n=275)\end{array}$ & $p$-value \\
\hline Multi-detector 64-slice spiral CT & $171(86.8 \%)$ & $75(96.2 \%)$ & $246(89.5 \%)$ & 0.02 \\
\hline Radiology interventional therapy & $131(66.5 \%)$ & $73(93.6 \%)$ & $204(74.2 \%)$ & $<0.001$ \\
\hline Hospital unit inpatient days & & & & $<0.001$ \\
\hline First quartile & $62(31.5 \%)$ & $6(7.7 \%)$ & $68(24.7 \%)$ & \\
\hline Second quartile & $58(29.4 \%)$ & $11(14.1 \%)$ & $69(25.1 \%)$ & \\
\hline Third quartile & $51(25.9 \%)$ & $18(23.1 \%)$ & $69(25.1 \%)$ & \\
\hline Fourth quartile & $26(13.2 \%)$ & $43(55.1 \%)$ & $69(25.1 \%)$ & \\
\hline Proportion of hospital unit Medicare discharges & & & & $<0.001$ \\
\hline Median (Q1, Q3) & $0.5(0.4,0.5)$ & $0.4(0.3,0.4)$ & $0.4(0.4,0.5)$ & \\
\hline Proportion of hospital unit Medicaid discharges & & & & $<0.001$ \\
\hline Median (Q1, Q3) & $0.1(0.1,0.2)$ & $0.2(0.2,0.3)$ & $0.2(0.1,0.2)$ & \\
\hline Number of Operating Rooms & & & & $<0.001$ \\
\hline Median (Q1, Q3) & $14(10.0,18.0)$ & $26(19.0,37.0)$ & $16(11.0,24.0)$ & \\
\hline Total surgical operations & & & & $<0.001$ \\
\hline \multirow[t]{2}{*}{ Median (Q1, Q3) } & 10,927 & 20,764 & 12,152 & \\
\hline & $(8018,15,101)$ & $(11,209,27,502)$ & $(8504,19,382)$ & \\
\hline Surgical intensity (Surgical procedures/inpatient beds/year) & & & & 0.31 \\
\hline \multirow[t]{2}{*}{ Median (Q1, Q3) } & 35.3 & 37.8 & 36.5 & \\
\hline & $(26.6,46.5)$ & $(30.1,48.4)$ & $(27.6,47.1)$ & \\
\hline Hospital total expenses & & & & $<0.001$ \\
\hline First quartile & $62(31.5 \%)$ & $6(7.7 \%)$ & $68(24.7 \%)$ & \\
\hline Second quartile & $60(30.5 \%)$ & $9(11.5 \%)$ & $69(25.1 \%)$ & \\
\hline Third quartile & $58(29.4 \%)$ & $11(14.1 \%)$ & $69(25.1 \%)$ & \\
\hline Fourth quartile & $17(8.6 \%)$ & $52(66.7 \%)$ & $69(25.1 \%)$ & \\
\hline Physician FTEs/10 beds & & & & 0.62 \\
\hline Median & 0.3 & 0.3 & 0.3 & \\
\hline Q1, Q3 & $0,1.1$ & $0,1.7$ & $0,1.2$ & \\
\hline Range & $(0-23.5)$ & $(0-24.6)$ & $(0-24.6)$ & \\
\hline Teaching Status & & & & $<0.001$ \\
\hline Nonteaching & $90(54.2 \%)$ & $18(24.7 \%)$ & $108(45.2 \%)$ & \\
\hline Minor teaching & $61(36.8 \%)$ & 15 (20.5\%) & $76(20.6 \%)$ & \\
\hline Major teaching & 15 (9.0\%) & $40(54.8 \%)$ & $55(54.8 \%)$ & \\
\hline FTEs nurses/10 beds & & & & $<0.001$ \\
\hline Median & 16.8 & 22.2 & 17.6 & \\
\hline Q1, Q3 & $13.8,19.9$ & $17.4,26.9$ & $14.3,22.3$ & \\
\hline Range & $(0.2-47.3)$ & $(0.2-41.6)$ & $(0.2-47.3)$ & \\
\hline \multicolumn{5}{|l|}{ Hospital Process Factors - Timely \& Effective Care: Heart Attack } \\
\hline Fibrinolytic therapy received within 30 min of ED arrival (percentage) & $N=58$ & $N=24$ & $N=82$ & 0.88 \\
\hline Median & 50 & 41.5 & 50 & \\
\hline Q1, Q3 & 0,100 & 0,100 & 0,100 & \\
\hline Aspirin at arrival (percentage) & $N=194$ & $N=77$ & $N=271$ & 0.18 \\
\hline Median & 100 & 100 & 100 & \\
\hline
\end{tabular}


Table 1 Differences in Demographic, Clinical, and Facility Characteristics among Kidney Transplant Patients Admitted with Cardiovascular Disease, by Transplant Hospital Status (Continued)

\begin{tabular}{|c|c|c|c|c|}
\hline \multicolumn{5}{|l|}{ Demographic and Clinical Characteristics } \\
\hline & $\begin{array}{l}\text { Non-transplant Hospital } \\
(n=197)\end{array}$ & $\begin{array}{l}\text { Transplant Hospital } \\
(n=78)\end{array}$ & $\begin{array}{l}\text { Total } \\
(n=275)\end{array}$ & $p$-value \\
\hline Q1, Q3 & 99,100 & 99,100 & 99,100 & \\
\hline Time to transfer to another facility for acute coronary intervention (minutes) & $N=37$ & $N=7$ & $N=44$ & 0.08 \\
\hline Median & 78 & 42 & 73.5 & \\
\hline Q1, Q3 & 57,105 & 30,121 & $51,106.5$ & \\
\hline Time to ECG (minutes) & $N=161$ & $N=51$ & $N=212$ & 0.01 \\
\hline Median & 11 & 16 & 12 & \\
\hline Q1, Q3 & 8,18 & 8,26 & 8,19 & \\
\hline \multicolumn{5}{|l|}{ Hospital Mortality and Unplanned Hospital Visits } \\
\hline Acute myocardial infarction 30-day mortality rate (percentage) & $N=183$ & $N=75$ & $N=258$ & 0.31 \\
\hline Median & 16.1 & 15.9 & 16 & \\
\hline Q1, Q3 & $15.1,17.1$ & $14.6,17.4$ & $14.9,17.1$ & \\
\hline Heart failure 30-day mortality rate (percentage) & $N=186$ & $N=76$ & $N=262$ & 0.10 \\
\hline Median & 10.9 & 10.7 & 10.8 & \\
\hline Q1, Q3 & 10,12 & $9.8,11.8$ & 10,12 & \\
\hline Acute myocardial infarction 30-day readmission rate (percentage) & $N=183$ & $N=76$ & $N=259$ & 0.13 \\
\hline Median & 20.1 & 20.5 & 20.2 & \\
\hline Q1, Q3 & $19.2,21.4$ & $19.7,21.5$ & $19.3,21.4$ & \\
\hline Heart failure 30-day readmission rate (percentage) & $N=186$ & $N=76$ & $N=262$ & 0.83 \\
\hline Median & 24.7 & 25.0 & 24.8 & \\
\hline Q1, Q3 & $23.4,26.6$ & $23.4,26.8$ & $23.4,26.7$ & \\
\hline
\end{tabular}

information criterion, lower values indicate better model fit. We expected to observe the highest QIC from the empty model with transplant status only, and the lowest QIC from the model with both patient and hospital characteristics.

\section{Determinants of high cost cardiovascular hospitalizations}

Hospitalizations were grouped into cost quartiles after conversion of hospitalization charges. We utilized the CART method and similarly structured GEEs as described above for mortality to determine the predictors of high cost hospitalization (highest cost quartile). The backward elimination technique was used to select the best model, and the variables with $p$-value $<0.4$ were retained in the model, and model fitness was assessed using QIC.

The project was exempt from IRB approval as the data utilized were publicly available and de-identified. The analysis was conducted in SAS 9.4 (SAS Institute) and in $\mathrm{R}$ 3.1.3 ( $\mathrm{R}$ Foundation for Statistical Computing). All tests were two-sided, and a $p$-value $<0.05$ was considered statistically significant.

\section{Results}

The final analysis sample consisted of 7803 hospital admissions from 275 hospitals from 2009 to 2011. Among the 275 hospitals, $28 \%(n=78)$ were kidney transplant facilities and $72 \%(n=197)$ were non-transplant facilities. Cardiovascular hospitalizations in the KT population were evenly distributed between NTHs $(n=3893$, $49.8 \%)$ and THs $(n=3910,50.1 \%)$. CHF and dysrhythmia were the leading causes of admission. The descriptive statistics for patient and hospital characteristics are shown in Table 1.

There were significant population differences in THs versus NTHs (Table 1). NTHs had more white patients. Multiple CVDs were coded in $24.3 \%$ of cases, more often at NTHs. NTHs had a significantly higher proportion of MI, CHF, and dysrhythmia admissions, while THs had more stroke, cardiac arrest, and malignant hypertension admissions. NTHs admitted significantly more patients with a high co-morbidity burden by Charlson score. Diabetes mellitus was commonly coded in hospitalizations at both types of facilities, and was present in the majority of admissions (>50\%). NTHs had a significantly greater proportion of emergent/ 
urgent admissions. NTHs demonstrated longer lengths of stay versus THs.

Facility characteristics differed between $\mathrm{TH}$ and NTHs. Cardiac intensive care was significantly more prevalent in THs vs. NTHs, but there was similar prevalence of specialty cardiac services in both hospital types. THs had significantly more surgical volume and daily occupancy. THs had significantly more technology (presence of 64-slice CT scanners and interventional radiology therapy). Case-mix was significantly different between the two hospital types, with THs had more Medicaid patients and NTHs had more Medicare. THs had higher total expenses, staffing ratios, and major teaching efforts compared to their counterparts.

Four cardiovascular process of care measures were available for analysis: time to receipt of fibrinolytic therapy, time to receipt of electrocardiogram, receipt of aspirin on hospital admission, and time to transfer to another facility for acute coronary intervention. THs and NTHs were similar in these, but these were not fully reported during the study period.

Table 2 demonstrates differences in mortality and proportion of high cost admissions stratified by primary cardiovascular diagnosis. THs and NTHs had similar rates of mortality and high cost admissions in MI, stroke, and dysrhythmia. Mortality from CHF was significantly higher in NTHs compared to THs, but had a similar proportion of high cost admissions. For patients admitted in cardiac arrest, mortality was similar, between 31 to $34 \%$, but $73.7 \%$ of those admissions were high cost in THs compared to $57.3 \%$ in NTHs.

\section{Hospital-specific mortality: crude and risk-adjusted analyses}

Overall in-hospital cardiovascular mortality was $3.4 \%$ (263/7802, with one admission with missing mortality information), and trended toward higher rates in NTHs versus THs $(3.8 \%$ vs. $3.0 \%, p=0.06)$. Figure 2 demonstrates variation in the distribution of hospital-specific cardiovascular mortality across all hospitals. Median hospital-specific mortality was $3.4 \%$, but varied significantly across hospitals (IQR $0-5.9 \%$, range $0-21 \%$ ). Hospital-specific mortality had a bimodal distribution, with more than a third of hospitals demonstrating more than 5\% cardiovascular mortality in KT recipients. Among higher mortality hospitals, there was a higher proportion of NTHs.

On multivariable analysis, we identified several clinical and hospital characteristics associated with mortality (Table 3). Importantly, sequential addition of patient and then hospital characteristics improved model performance by QIC. TH status was not associated with mortality, even after including patient and hospital characteristics. Multiple clinical characteristics were important drivers of mortality. Age, burden of cardiovascular diagnoses, and utilization of diagnostic cardiac catheterization (but not therapeutic catheterization) were associated with significantly higher mortality, respectively. Female sex, non-white race, and documentation of co-morbidities (diabetes mellitus and dyslipidemia) were associated with lower mortality, respectively. Admission to a cardiovascular destination hospital (high proportion of cohort patients transferred in this facility), and hospitals with long lengths of stay were factors associated with mortality. The only hospital factor that was protective from mortality was major teaching status, which reduced the odds of mortality by $68 \%$ compared to non-teaching facilities (OR 0.32, $p=0.002$ ). Cardiovascular process of care measures including time to ECG and ASA administration at arrival were not significant predictors of mortality.

Table 2 Variation in mortality and high cost admissions by diagnosis and transplant hospital status

\begin{tabular}{|c|c|c|c|c|c|c|}
\hline \multirow[t]{2}{*}{ Primary CV diagnosis } & \multicolumn{3}{|l|}{ Mortality } & \multicolumn{3}{|c|}{ High cost (in the top quartile) } \\
\hline & Non-transplant hospital & Transplant hospital & $p$-value & Non-transplant hospital & Transplant hospital & $p$-value \\
\hline \multirow[t]{2}{*}{ MI (410.x) } & $7.0 \%$ & $7.9 \%$ & 0.68 & $44.3 \%$ & $51.2 \%$ & 0.10 \\
\hline & $(27 / 383)$ & $(24 / 305)$ & & $(143 / 323)$ & $(125 / 244)$ & \\
\hline \multirow[t]{2}{*}{ Stroke (997.x/436/437.1) } & $5.7 \%$ & $3.5 \%$ & 0.17 & $41.1 \%$ & $45.1 \%$ & 0.34 \\
\hline & $(14 / 247)$ & $(16 / 461)$ & & $(85 / 207)$ & $(185 / 410)$ & \\
\hline \multirow[t]{2}{*}{ CHF (428.x) } & $3.4 \%$ & $2.3 \%$ & 0.04 & $23.1 \%$ & $24.1 \%$ & 0.48 \\
\hline & $(72 / 2110)$ & $(46 / 1968)$ & & $(417 / 1807)$ & $(389 / 1614)$ & \\
\hline \multirow[t]{2}{*}{ Dysrhythmia (427.x) } & $4.7 \%$ & $4.0 \%$ & 0.25 & $21.5 \%$ & $27.3 \%$ & $<0.001$ \\
\hline & $(101 / 2138)$ & $(81 / 2027)$ & & $(395 / 1838)$ & $(466 / 1704)$ & \\
\hline \multirow[t]{2}{*}{ Cardiac arrest (427.5/997.1) } & $34.1 \%$ & $31.4 \%$ & 0.69 & $57.3 \%$ & $73.5 \%$ & 0.03 \\
\hline & $(29 / 85)$ & $(32 / 102)$ & & $(43 / 75)$ & $(61 / 83)$ & \\
\hline \multirow[t]{2}{*}{ Malignant HTN (402.x) } & 0 & 0 & & $9.3 \%$ & $13.2 \%$ & 0.49 \\
\hline & & & & $(5 / 54)$ & $(10-76)$ & \\
\hline
\end{tabular}




\section{Variation in Cardiovascular Mortality in Kidney Transplant Patients Across U.S. Hospitals}

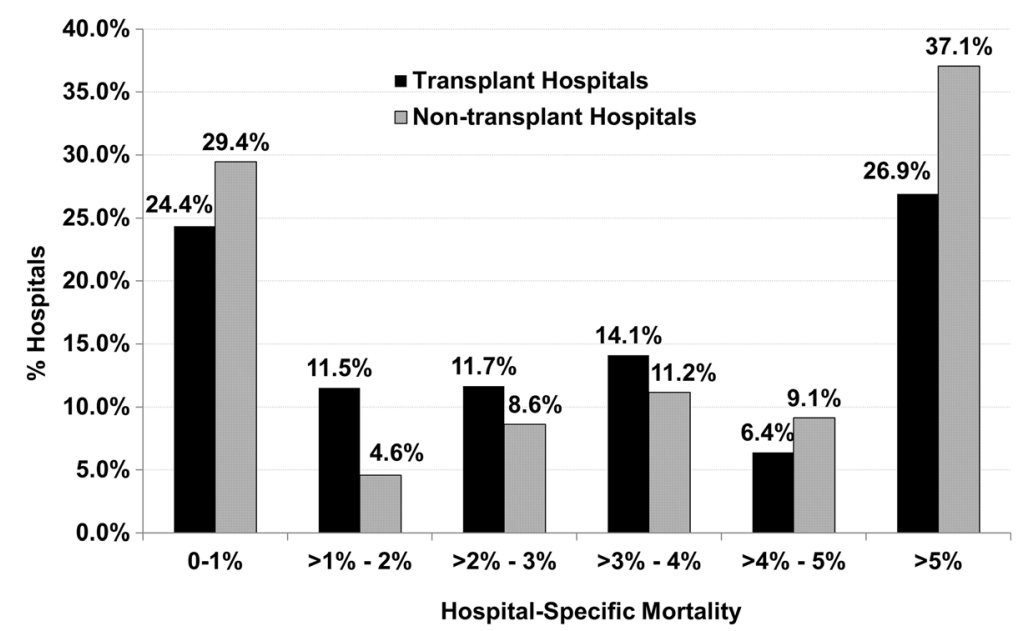

Fig. 2 Variation in cardiovascular mortality in kidney transplant patients across U.S. hospitals. Across a broad sample of hospitals in the United States, among kidney transplant recipients, there was tremendous variation noted in un-adjusted mortality for patients admitted with a cardiovascular disease process (including myocardial infarction, stroke, congestive heart failure, dysrhythmia, cardiac arrest, or malignant hypertension). The overall hospital mortality was 3.4\%, but had a wide range. The crude mortality trends indicated that non-transplant hospitals were over-represented in both low and high mortality outlier groups. A greater proportion of non-transplant hospitals (37.1\%) were designated as high mortality hospitals (> 5\%) compared to transplant hospitals (26.9\%). This relationship was not uniform across all hospital-specific mortality categories, which warranted further analysis using multivariate hierarchical models

\section{Hospital-specific hospitalization cost: crude and risk- adjusted analyses}

Figure 3 demonstrates the significant variation observed in median hospital costs for these admissions. Hospitals varied by nearly six-fold in costs of cardiovascular care in post-KT population. $20 \%$ of hospitalizations, as in Table 1, included cardiovascular procedures including cardiac catheterization or cardiac surgery.

Clinical and hospital characteristics were also associated with high cost hospitalizations ( $\mathrm{HCHs}$ ) (Table 4). On univariate analysis, THs were associated with $\mathrm{HCH}$, but after risk-adjustment for both clinical and other hospital characteristics, THs were associated with significantly lower costs than NTHs. Older age and cardiovascular disease burden were associated with significantly higher odds of $\mathrm{HCH}$. Emergent admissions were associated with $46 \%$ lower odds of being $\mathrm{HCH}$ compared to elective admissions $(p<0.001)$. Cardiovascular procedures were associated with $\mathrm{HCH}$, including diagnostic and therapeutic catheterization, coronary artery bypass grafting, and other cardiac surgery. Higher Medicare payer-mix was a negative predictor for $\mathrm{HCH}$. Higher physician staffing levels was also associated with $\mathrm{HCH}$. The addition of patient and hospital characteristics to $\mathrm{TH}$ status led to notable reduction in QIC, suggesting better model fitness.

As a sensitivity analysis, we included the $14.2 \%$ of hospitalization episodes with inpatient dialysis codes to assess the effect of $\mathrm{TH}$ status on mortality and costs when including these hospitalization episodes. Among episodes with dialysis use, there was no differences between THs and NTHs in mortality (THs vs NTHs: $5.9 \%$ vs. $7.0 \%, p=0.51$ ) or high costs admissions (THs vs NTHs: $28.3 \%$ vs. $34.5 \%, p=0.06$ ) on univariate analysis. On multi-variate analysis, Dialysis use did not modify the effect of THs on mortality (no effect of TH status) or high cost care (THs were predictive of lower likelihood of having a high cost episode) (interaction terms for dialysis-transplant hospital status: mortality model $p=0.18$, high cost care $p=0.9$ ). Furthermore, the significant predictors associated with mortality and high cost care did not change, nor was there any notable change in effect size in these models.

\section{Discussion}

We have previously identified two important trends in health care utilization for cardiovascular disease in the transplant population, which fueled our interest in this study. First, utilization of hospital services for cardiovascular disease in the kidney transplant recipients is growing, particularly in non-transplant hospitals and secondly, there was a trend toward higher mortality in these hospitals [5]. By studying a large database of hospitalization episodes and linking it to granular data on hospital characteristics, we were able to design models to identify clinical risk factors and hospital 
Table 3 Characteristics Associated with Inpatient Mortality from Cardiovascular Disease after Kidney Transplantation

\begin{tabular}{|c|c|c|c|c|c|c|c|c|c|c|c|c|}
\hline \multirow{3}{*}{$\begin{array}{l}\text { Variable } \\
\text { Transplant hospital }\end{array}$} & \multirow{3}{*}{$\begin{array}{l}\text { Comparison } \\
\text { Transplant vs. Non-transplant }\end{array}$} & \multicolumn{3}{|c|}{$\begin{array}{l}\text { Model 1: Transplant } \\
\text { Hospital Only }\end{array}$} & \multicolumn{4}{|c|}{$\begin{array}{l}\text { Model 2: Transplant } \\
\text { Hospital + Patient } \\
\text { Characteristics }\end{array}$} & \multicolumn{4}{|c|}{$\begin{array}{l}\text { Model 3: Transplant } \\
\text { Hospital + Patient } \\
\text { Characteristics + Hospital } \\
\text { Characteristics }\end{array}$} \\
\hline & & \multirow{2}{*}{$\begin{array}{l}\mathrm{OR} \\
0.81\end{array}$} & $95 \% \mathrm{Cl}$ & \multirow{2}{*}{$\frac{p \text {-value }}{0.16}$} & \multirow{2}{*}{$\begin{array}{l}\text { OR } \\
0.72\end{array}$} & \multicolumn{2}{|c|}{$95 \% \mathrm{Cl}$} & \multirow{2}{*}{$\frac{p \text {-value }}{0.11}$} & \multirow{2}{*}{$\begin{array}{l}\text { OR } \\
0.98\end{array}$} & \multicolumn{2}{|c|}{$95 \% \mathrm{Cl}$} & \multirow{2}{*}{$\frac{p \text {-value }}{0.94}$} \\
\hline & & & 0.601 .09 & & & 0.48 & 1.08 & & & 0.50 & 1.91 & \\
\hline \multicolumn{13}{|l|}{ Patient-level Characteristics } \\
\hline Age & $\geq 60$ vs. $<60$ & & & & 2.28 & 1.53 & 3.4 & $<0.001$ & 2.29 & 1.37 & 3.85 & 0.002 \\
\hline Race & Non-white vs. White & & & & 0.62 & 0.39 & 0.99 & 0.04 & 0.49 & 0.26 & 0.9 & 0.02 \\
\hline Sex & Female vs. Male & & & & 0.69 & 0.47 & 1.02 & 0.06 & 0.59 & 0.37 & 0.92 & 0.02 \\
\hline Type of admission & $\begin{array}{l}\text { Emergent/Urgent vs. Elective/ } \\
\text { Others }\end{array}$ & & & & 1.37 & 0.73 & 2.56 & 0.33 & 1.5 & 0.69 & 3.26 & 0.30 \\
\hline $\begin{array}{l}\text { Admitted to high transfer in } \\
\text { hospital }\end{array}$ & Yes vs. No & & & & 1.52 & 1.02 & 2.27 & 0.04 & 1.76 & 1.01 & 3.05 & 0.05 \\
\hline Number of CV diagnosis & $\geq 2$ vs. 1 & & & & 2.09 & 1.44 & 3.03 & $<0.001$ & 1.73 & 1.08 & 2.78 & 0.02 \\
\hline Weighted Charlson score & $\geq 2$ vs. $0-1$ & & & & 1.37 & 0.89 & 2.12 & 0.16 & 1.06 & 0.63 & 1.81 & 0.82 \\
\hline Hypertension & Yes vs. No & & & & 1.11 & 0.64 & 1.93 & 0.71 & 1.26 & 0.61 & 2.57 & 0.53 \\
\hline Tobacco abuse & Yes vs. No & & & & 0.39 & 0.09 & 1.68 & 0.21 & 0.24 & 0.03 & 2.05 & 0.19 \\
\hline Dyslipidemia & Yes vs. No & & & & 0.48 & 0.31 & 0.75 & 0.001 & 0.58 & 0.35 & 0.98 & 0.04 \\
\hline Diabetes mellitus & Yes vs. No & & & & 0.46 & 0.31 & 0.66 & $<0.001$ & 0.4 & 0.25 & 0.64 & $<0.001$ \\
\hline \multicolumn{13}{|l|}{ Invasive CV procedure } \\
\hline $\begin{array}{l}\text { Diagnostic Cardiac } \\
\text { catheterization }\end{array}$ & Yes vs. No & & & & 2.60 & 1.76 & 3.84 & $<0.001$ & 2.1 & 1.32 & 3.36 & 0.002 \\
\hline $\begin{array}{l}\text { Therapeutic cardiac } \\
\text { catheterization }\end{array}$ & Yes vs. No & & & & 0.22 & 0.07 & 0.67 & 0.008 & 0.35 & 0.1 & 1.17 & 0.09 \\
\hline CABG & Yes vs. No & & & & 0.23 & 0.06 & 0.93 & 0.04 & 0.35 & 0.07 & 1.65 & 0.18 \\
\hline Valve surgery & Yes vs. No & & & & 0.51 & 0.12 & 2.12 & 0.35 & 0.38 & 0.07 & 1.95 & 0.25 \\
\hline Other cardiac surgery & Yes vs. No & & & & 2.94 & 0.79 & 11.01 & 0.11 & 1.26 & 0.2 & 7.88 & 0.81 \\
\hline \multicolumn{13}{|l|}{ Hospital-level Characteristics } \\
\hline \multicolumn{13}{|l|}{ Owner, Financial status, Payer Mix } \\
\hline \multirow{3}{*}{$\begin{array}{l}\text { Hospital total expenses by } \\
\text { quartile }\end{array}$} & 2 vs. 1 & & & & & & & & 1.45 & 0.64 & 3.27 & 0.38 \\
\hline & 3 vs. 1 & & & & & & & & 0.52 & 0.16 & 1.68 & 0.28 \\
\hline & 4 vs. 1 & & & & & & & & 0.26 & 0.07 & 0.97 & 0.05 \\
\hline \multicolumn{13}{|l|}{ Inpatient Capacity } \\
\hline \multirow{3}{*}{$\begin{array}{l}\text { Hospital unit inpatient days by } \\
\text { quartile }\end{array}$} & 2 vs. 1 & & & & & & & & 0.53 & 0.21 & 1.3 & 0.16 \\
\hline & 3 vs. 1 & & & & & & & & 1.02 & 0.34 & 3.11 & 0.97 \\
\hline & 4 vs. 1 & & & & & & & & 4.26 & 1.2 & 15.21 & 0.03 \\
\hline Cardiac intensive care & Yes vs. No & & & & & & & & 1.75 & 0.78 & 3.91 & 0.18 \\
\hline \multicolumn{13}{|l|}{ Staffing Patterns } \\
\hline \multirow[t]{2}{*}{ Teaching status } & $\begin{array}{l}\text { Minor teaching vs. } \\
\text { Nonteaching }\end{array}$ & & & & & & & & 0.65 & 0.37 & 1.15 & 0.14 \\
\hline & $\begin{array}{l}\text { Major teaching vs. } \\
\text { Nonteaching }\end{array}$ & & & & & & & & 0.32 & 0.16 & 0.65 & 0.002 \\
\hline \multicolumn{13}{|l|}{ Process of Care for Heart Attack } \\
\hline Aspirin at arrival & Per $5 \%$ increase & & & & & & & & 2.28 & 0.58 & 9.07 & 0.24 \\
\hline Time to ECG & Per 20 min increase & & & & & & & & 0.98 & 0.81 & 1.19 & 0.85 \\
\hline QIC & & 1758. & & & 1095 & & & & 736.4 & & & \\
\hline
\end{tabular}




\section{Variation in Median Hospital Costs for Cardiovascular Disease Hospitalizations in Kidney Transplant Patients Across U.S. Hospitals}

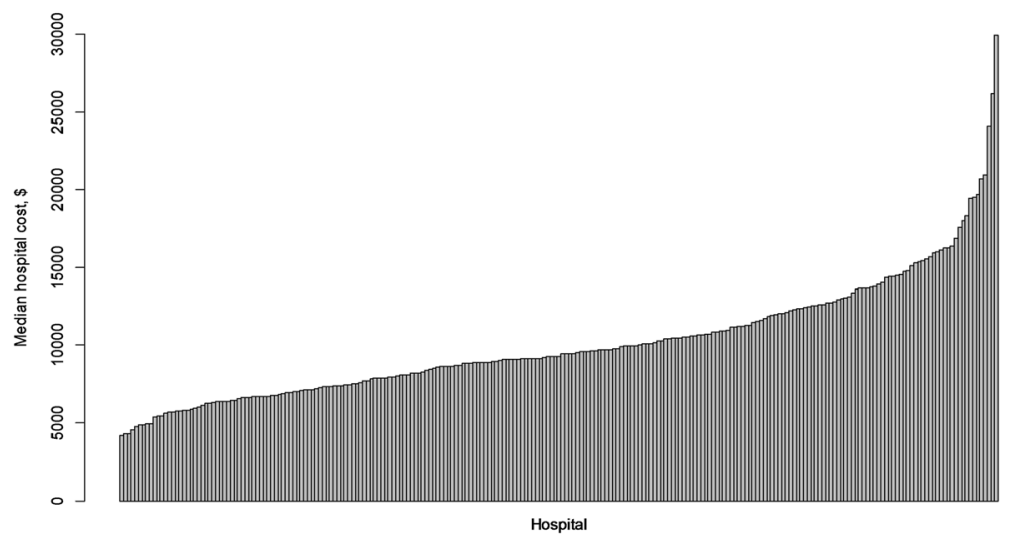

Fig. 3 Variation in median hospital costs for cardiovascular disease hospitalizations in kidney transplant patients across U.S. hospitals. Similar to variation in hospital mortality, we observed vast differences in median hospital costs for inpatient care for cardiovascular disease among kidney transplant recipients. Each bar represents an individual hospital in the analysis, and the degree of median cost-variation varied nearly six-fold

characteristics predictive of adverse clinical and financial outcomes.

An important early finding in the analysis was a concerning trend toward higher inpatient cardiovascular mortality in NTHs. After adjusting for clinical and facility characteristics, THs and NTHs had similar mortality. Clinical factors largely mediated this difference. From the group of facility factors, only teaching status was associated with lower mortality, which was recently also observed by Silber et al. in a Medicare study on MI patients [12]. Predictors of mortality and $\mathrm{HCH}$ included age and cardiovascular disease burden (based on the number of coded cardiovascular diagnoses) and utilization of diagnostic cardiac catheterization. Machinicki et al. has previously shown that pre-existing cardiovascular disease burden can reliably predict Medicare mortality and costs in the 3 years following transplantation [20]. Cardiovascular procedures were associated with a lower risk of mortality and higher costs compared to non-procedural admissions, likely related to resources utilized and patient selection in these admissions versus others.

An interesting finding was related to costs of care. While NTHs had longer lengths of stay for the same diagnoses, other significant facility factors were associated with lower costs: higher Medicare payer-mix, lower physician staffing, and TH status. This may imply THs provide better value in managing CVD complications, considering THs and NTHs had similar odds of population-based mortality. Why would this be the case? THs are resource-intense facilities and typically carry significant resources and expertise. This may translate into better value by reducing unnecessary testing or care intensity [21], and could be related to patients being in their "transplant home" where they are a known entity. Practice patterns, in this context, likely differ between THs and NTHs and drive observed differences in HCHs. This finding is novel, and generates a hypothesis that warrants further analysis within specific diagnoses, and potentially with richer clinical data.

This study has direct implications for clinical practice and care models aimed at rescuing post-transplant patients in high-risk cardiovascular scenarios. Prevention of cardiovascular events is key. These events are increasingly recognized and inpatient mortality exceeds 3\% [811, 14, 20, 22-24]. Risk factor modification should be a central tenet of post-transplant care. Increasing access to preventive cardiology, alterations in immunosuppression, adherence to cardio-protective medication regimens, and application of guideline-based cardiovascular medical therapy may improve outcomes in the post-transplant population $[25,26]$. Secondly, our analysis suggests that certain clinical phenotypes are at high risk for mortality older kidney transplant patients with multiple cardiovascular diagnoses who require invasive interventions. As observed here, transplant patients pursue complex care in all types of facilities - our study indicates that NTHs are associated with reasonable outcomes. This represents a shift from earlier years of clinical transplantation, likely related to greater prevalence of transplant patients in the community and the proliferation of well-resourced hospitals around the country. This shift also warrants the development of formal and informal care networks within communities to manage these patients. Non-transplant providers/facilities take on significant risk with these patients, and transplant providers/hospitals should support 
Table 4 Characteristics Associated with High Cost Hospitalizations from Cardiovascular Disease after Kidney Transplantation

\begin{tabular}{|c|c|c|c|c|c|c|c|c|c|c|c|c|}
\hline \multirow{3}{*}{$\begin{array}{l}\text { Variable } \\
\text { Transplant hospital }\end{array}$} & \multirow{3}{*}{$\begin{array}{l}\text { Comparison } \\
\\
\text { Transplant vs. Non- } \\
\text { transplant }\end{array}$} & \multicolumn{3}{|c|}{$\begin{array}{l}\text { Model 1: Transplant } \\
\text { Hospital Only }\end{array}$} & \multicolumn{4}{|c|}{$\begin{array}{l}\text { Model 2: Transplant } \\
\text { Hospital + Patient } \\
\text { Characteristics }\end{array}$} & \multicolumn{4}{|c|}{$\begin{array}{l}\text { Model 3: Transplant } \\
\text { Hospital + Patient } \\
\text { Characteristics + Hospital } \\
\text { Characteristics }\end{array}$} \\
\hline & & \multirow{2}{*}{$\begin{array}{l}\mathrm{OR} \\
1.26\end{array}$} & $95 \% \mathrm{Cl}$ & \multirow{2}{*}{$\frac{p \text {-value }}{0.02}$} & \multirow{2}{*}{$\begin{array}{l}\mathrm{OR} \\
1.46\end{array}$} & \multicolumn{2}{|c|}{$95 \% \mathrm{Cl}$} & \multirow{2}{*}{$\frac{p \text {-value }}{0.002}$} & \multirow{2}{*}{$\begin{array}{l}\mathrm{OR} \\
0.66\end{array}$} & \multicolumn{2}{|c|}{$95 \% \mathrm{Cl}$} & \multirow{2}{*}{$\frac{p \text {-value }}{0.02}$} \\
\hline & & & 1.041 .53 & & & 1.16 & 1.85 & & & 0.47 & 0.94 & \\
\hline \multicolumn{13}{|l|}{ Patient-level Characteristics } \\
\hline Age & $\geq 60$ vs. $<60$ & & & & 1.17 & 0.98 & 1.40 & 0.08 & 1.30 & 1.05 & 1.61 & 0.02 \\
\hline Race & Non-white vs. White & & & & 0.89 & 0.74 & 1.08 & 0.25 & 0.87 & 0.70 & 1.10 & 0.25 \\
\hline Sex & Female vs. Male & & & & 0.95 & 0.80 & 1.13 & 0.57 & 1.05 & 0.86 & 1.30 & 0.62 \\
\hline Type of admission & $\begin{array}{l}\text { Emergent/Urgent vs. } \\
\text { Elective/Others }\end{array}$ & & & & 0.55 & 0.43 & 0.69 & $<0.001$ & 0.54 & 0.40 & 0.72 & $<0.001$ \\
\hline $\begin{array}{l}\text { Admitted to high transfer in } \\
\text { hospital }\end{array}$ & Yes vs. No & & & & 0.97 & 0.75 & 1.25 & 0.81 & 1.07 & 0.82 & 1.40 & 0.61 \\
\hline Number of CV diagnosis & $\geq 2$ vs. 1 & & & & 1.36 & 1.16 & 1.59 & $<0.001$ & 1.55 & 1.25 & 1.93 & $<0.001$ \\
\hline Weighted Charlson score & $\geq 2$ vs. $0-1$ & & & & 1.08 & 0.86 & 1.35 & 0.51 & 1.05 & 0.80 & 1.39 & 0.71 \\
\hline Hypertension & Yes vs. No & & & & 0.88 & 0.69 & 1.12 & 0.31 & 0.76 & 0.56 & 1.05 & 0.09 \\
\hline Tobacco abuse & Yes vs. No & & & & 0.65 & 0.42 & 1.00 & 0.05 & 0.68 & 0.37 & 1.27 & 0.23 \\
\hline Dyslipidemia & Yes vs. No & & & & 0.79 & 0.67 & 0.94 & 0.006 & 0.80 & 0.64 & 1.01 & 0.06 \\
\hline Diabetes mellitus & Yes vs. No & & & & 0.89 & 0.76 & 1.06 & 0.18 & 0.89 & 0.72 & 1.10 & 0.29 \\
\hline \multicolumn{13}{|l|}{ Invasive CV procedure } \\
\hline $\begin{array}{l}\text { Diagnostic Cardiac } \\
\text { catheterization }\end{array}$ & Yes vs. No & & & & 3.65 & 2.98 & 4.47 & $<0.001$ & 4.51 & 3.46 & 5.89 & $<0.001$ \\
\hline $\begin{array}{l}\text { Therapeutic cardiac } \\
\text { catheterization }\end{array}$ & Yes vs. No & & & & 3.11 & 1.79 & 5.41 & $<0.001$ & 3.08 & 1.57 & 6.04 & 0.001 \\
\hline CABG & Yes vs. No & & & & 17.91 & 3.79 & 84.61 & $<0.001$ & 25.48 & 2.65 & 244.93 & 0.005 \\
\hline Valve surgery & Yes vs. No & & & & 6.68 & 1.30 & 34.31 & 0.02 & 13.63 & 0.66 & 281.03 & 0.09 \\
\hline Other cardiac surgery & Yes vs. No & & & & 4.06 & 1.79 & 9.23 & $<0.001$ & 3.88 & 1.13 & 13.31 & 0.03 \\
\hline \multicolumn{13}{|l|}{ Hospital-level Characteristics } \\
\hline \multicolumn{13}{|c|}{ Owner, Financial status, Payer Mix } \\
\hline \multirow{3}{*}{$\begin{array}{l}\text { Hospital total expenses by } \\
\text { quartile }\end{array}$} & 2 vs. 1 & & & & & & & & 1.37 & 0.76 & 2.49 & 0.30 \\
\hline & 3 vs. 1 & & & & & & & & 1.73 & 0.89 & 3.38 & 0.11 \\
\hline & 4 vs. 1 & & & & & & & & 1.40 & 0.63 & 3.13 & 0.41 \\
\hline PPO Hospital & Yes vs. No & & & & & & & & 1.34 & 0.80 & 2.25 & 0.27 \\
\hline \% Medicare discharge & Per $10 \%$ increase & & & & & & & & 0.69 & 0.60 & 0.80 & $<0.001$ \\
\hline \multicolumn{13}{|l|}{ Inpatient Capacity } \\
\hline \multirow{3}{*}{$\begin{array}{l}\text { Hospital unit inpatient days } \\
\text { by quartile }\end{array}$} & 2 vs. 1 & & & & & & & & 1.15 & 0.64 & 2.06 & 0.65 \\
\hline & 3 vs. 1 & & & & & & & & 0.91 & 0.48 & 1.74 & 0.77 \\
\hline & 4 vs. 1 & & & & & & & & 1.03 & 0.50 & 2.12 & 0.93 \\
\hline \multicolumn{13}{|l|}{ Staffing Patterns } \\
\hline Physician FTE/10 beds & Per 1 FTE increase & & & & & & & & 1.05 & 1.03 & 1.07 & $<0.001$ \\
\hline Nurse FTE/10 beds & Per 1 FTE increase & & & & & & & & 1.01 & 1.00 & 1.03 & 0.18 \\
\hline \multicolumn{13}{|l|}{ Process of Care for Heart Attack } \\
\hline Aspirin at arrival & Per $5 \%$ increase & & & & & & & & 1.18 & 0.62 & 2.24 & 0.62 \\
\hline Time to ECG & Per 20 min increase & & & & & & & & 0.99 & 0.92 & 1.07 & 0.85 \\
\hline QIC & & 6258. & & & 4193.5 & & & & 2466.62 & & & \\
\hline
\end{tabular}


them. Formal and informal partnerships underscored by clear inter-facility communication are vital. The development of these networks requires earnest collaboration, and both transplant and non-transplant hospitals have the incentives to do so. Further research evaluating the effectiveness of these networks would be an interesting innovation in studying transplant health services.

This analysis has limitations. Since each record in the data represented a single unlinked hospitalization, the timing of the transplant relative to the cardiovascular event is unknown. Linkage of admissions would have enriched the observations in this analysis, and may have helped elucidate potential interventions for future studies. Administrative data inherently lack clinical granularity which limits our ability to see the true biological effects of documented co-morbidities on in-hospital mortality and costs, such as diabetes and dyslipidemia. The Donabedian model of health care quality prioritizes processes of care, but cardiovascular process measures were not associated with outcomes in this analysis. While these vary between hospitals, they may not be applicable to transplant patient outcomes, or have any effect on outcomes at all [27-29]. All secondary data analyses provide the net effect of specific clinical and hospital-level covariates on outcomes across the entire population, and are subject to the ecological fallacy when evaluating individual outcomes. The effects observed here may also not reflect more recent practice patterns or hospital structural improvements that may affect mortality and costs today.

Adverse outcomes from cardiovascular events impact post-KT survival. Further research is needed to reduce the risk of mortality once an event occurs. Costs related to prevention and cost-effectiveness of event-based care warrant further analysis. These efforts will improve care for transplant patients, optimize rescue in acute settings, reduce post-transplant costs, and extend long-term posttransplant survival.

\section{Conclusions}

Using administrative data, this analysis indicates that transplant and non-transplant hospitals had similar riskadjusted mortality when managing cardiovascular events in previous kidney transplant recipients. Transplant hospitals were less likely to have high cost episodes of care for these events, which may imply better value in posttransplant cardiovascular care delivery. These data have significant implications for patients, transplant and nontransplant providers, and payers.

\section{Abbreviations}

CART: Classification and Regression Tree; CHF: Congestive heart failure; CT: Computed tomography; CVA: Cerebrovascular accident / stroke; CVD: Cardiovascular disease; GEE: Generalized estimation equations; HCUP: Healthcare Cost and Utilization Project; ICD: 9th International
Classification of Disease codes; MI: Myocardial infarction; NIS: Nationwide Inpatient Sample; QIC: Quasi-likelihood under independence criterion

\section{Acknowledgements}

None

Funding

No external funds were used for this study.

Availability of data and materials

The data used in this article are publicly-available are available from the corresponding author on reasonable request.

\section{Authors' contributions}

All authors have reviewed and approved the final version of the manuscript. AKM: all aspects including conception of study idea, design, data acquisition, data analysis and interpretation, writing of manuscript, study supervision. YHC: all aspects of the study including conception of study idea, design, data acquisition, data analysis and interpretation, writing of manuscript. DES: study design, data analysis and interpretation, writing of manuscript. RLH: data analysis and interpretation, and writing of manuscript. NW: study design, data analysis and interpretation, writing of manuscript. DE: study design, data analysis and interpretation, writing of manuscript. KSR: study design, data analysis and interpretation, writing of manuscript. AAM: study design, data analysis and interpretation, writing of manuscript, supervision.

Ethics approval and consent to participate

Data derived directly from human subjects was not required in this study. This study was exempt from IRB review due to use of de-identified data in established administrative datasets.

\section{Consent for publication}

N/A

\section{Competing interests}

The authors declare that they have no competing interests.

\section{Publisher's Note}

Springer Nature remains neutral with regard to jurisdictional claims in published maps and institutional affiliations.

\section{Author details}

${ }^{1}$ Division of Transplant Surgery, Department of Surgeyr, Mayo Clinic Arizona, 5777 East Mayo Boulevard, Phoenix, AZ 85054, USA. ${ }^{2}$ Robert D. and Patricia E. Kern Center for the Science of Health Care Delivery, Mayo Clinic, Phoenix, AZ, USA. ${ }^{3}$ Division of Cardiovascular Medicine, Mayo Clinic Arizona, Phoenix, AZ, USA. ${ }^{4}$ Division of Nephrology, Mayo Clinic Arizona, Phoenix, AZ, USA.

Received: 16 December 2018 Accepted: 17 May 2019

Published online: 28 May 2019

\section{References}

1. Bilancio G, Celano M, Cozza V, Zingone F, Palladino G, Cirillo M. Early prediction of cardiovascular disease in kidney transplant recipients. Transplant Proc. 2017;49(9):2092-8.

2. Ballesteros F, Allard J, Durand C, Cardinal H, Lalonde L, Fortin MC. Kidney transplant Recipients' perspectives on cardiovascular disease and related risk factors after transplantation: a qualitative study. Transplant Direct. 2017;3(6): e162.

3. Kolonko A, Chudek J, Szotowska M, Kuczera P, Wiecek A. Cardiovascular risk factors and markers of atherosclerosis in stable kidney transplant recipients. Transplant Proc. 2016:48(5):1543-50.

4. Delville M, Sabbah L, Girard D, Elie C, Manceau S, Piketty M, et al. Prevalence and predictors of early cardiovascular events after kidney transplantation: evaluation of pre-transplant cardiovascular work-up. PLoS One. 2015;10(6): e0131237

5. Mathur AK, Chang Y-H, Steidley DE, Heilman R, Khurmi N, Wasif N, et al. Patterns of care and outcomes in cardiovascular disease after kidney transplantation in the United States. Transplant Direct. 2017;3(2):e126. 
6. Khurmi NS, Chang YH, Steidley DE, Singer AL, Hewitt WR, Reddy KS, Moss AA, Mathur AK. Hospitalizations for Cardiovascular Disease After Liver Transplantation in the United States. Liver Transpl. 2018;24(10):1398-410.

7. Lentine $\mathrm{KL}$, Hurst FP, Jindal RM, Villines TC, Kunz JS, Yuan CM, et al. Cardiovascular risk assessment among potential kidney transplant candidates: approaches and controversies. Am J Kidney Dis. 2010;55(1): 152-67.

8. Abbott KC, Bohen EM, Yuan CM, Yeo FE, Sawyers ES, Perkins RM, et al. Use of beta-blockers and aspirin after myocardial infarction by patient renal function in the Department of Defense health care system. Am J Kidney Dis. 2006;47(4):593-603.

9. Lentine KL, Schnitzler MA, Brennan DC, Snyder JJ, Hauptman PJ, Abbott KC, et al. Cardiac evaluation before kidney transplantation: a practice patterns analysis in Medicare-insured dialysis patients. Clin J Am Soc Nephrol. 2008; 3(4):1115-24.

10. Schnitzler MA, Salvalaggio PR, Axelrod DA, Lentine KL, Takemoto SK. Lack of interventional studies in renal transplant candidates with elevated cardiovascular risk. Am J Transplant Off J Am Soc Transplant Am Soc Transplant Surg. 2007;7(3):493-4.

11. Agrawal S, Garg L, Garg A, Mohananey D, Jain A, Manda Y, et al. Recent trends in management and Inhospital outcomes of acute myocardial infarction in renal transplant recipients. Am J Cardiol. 2017;119(4):542-52.

12. Silber JH, Arriaga AF, Niknam BA, Hill AS, Ross RN, Romano PS. Failure-torescue after acute myocardial infarction. Med Care. 2018;56(5):416-23.

13. Mathur AK, Chang Y-H, Steidley DE, Katariya NN, Singer AL, Hewitt WR, et al. Hospitalizations for cardiovascular disease after kidney transplantation: the role of facility characteristics on outcomes and costs. Am J Transplant. 2016; 16(S3):578.

14. Lentine KL, Schnitzler MA, Abbott KC, Bramesfeld K, Buchanan PM, Brennan DC. Sensitivity of billing claims for cardiovascular disease events among kidney transplant recipients. Clin J Am Soc Nephrol. 2009;4(7):1213-21.

15. Ellimoottil C, Ye Z, Chakrabarti AK, Englesbe MJ, Miller DC, Wei JT, et al. Understanding inpatient cost variation in kidney transplantation: implications for payment reforms. Urology. 2016;87:88-94.

16. Bureau of Economic Analysis, U.S. Department of Commerce. National Income and Product Accounts Table. In. http://www.bea.gov/iTable/iTable. $\mathrm{cfm}$ ?reqid $=9 \&$ step $=3 \&$ isuri $=1 \& 903=13 \#$ reqid $=9 \&$ step $=3 \&$ isuri $=1 \& 903=13$, 2016.

17. Liang KY, Zeger SL. Longitudinal data-analysis using generalized linearmodels. Biometrika. 1986;73(1):13-22.

18. Breiman L, Friedman JH, Stone CJ, Olshen RA. Classification and regression trees. Pacific Grove: Wadsworth; 1984

19. Pan W. Akaike's information criterion in generalized estimating equations. Biometrics. 2001;57(1):120-5.

20. Machnicki G, Lentine KL, Salvalaggio PR, Burroughs TE, Brennan DC, Schniztler MA. Three-year post-transplant Medicare payments in kidney transplant recipients: associations with pre-transplant comorbidities. Saudi J Kidney Dis Transpl. 2011;22(1):24-39.

21. Xu X, Li SX, Lin H, Normand SL, Kim N, Ott LS, et al. "Phenotyping" hospital value of care for patients with heart failure. Health Serv Res. 2014;49(6): 2000-16.

22. Machnicki G, Pinsky B, Takemoto S, Balshaw R, Salvalaggio PR, Buchanan PM, et al. Predictive ability of pretransplant comorbidities to predict long-term graft loss and death. Am J Transplant. 2009;9(3):494-505.

23. Lentine KL, Costa SP, Weir MR, Robb JF, Fleisher LA, Kasiske BL, et al. Cardiac disease evaluation and management among kidney and liver transplantation candidates: a scientific statement from the American Heart Association and the American College of Cardiology Foundation: endorsed by the American Society of Transplant Surgeons, American Society of Transplantation, and National Kidney Foundation. Circulation. 2012;126(5): 617-63.

24. Stoumpos S, Jardine AG, Mark PB. Cardiovascular morbidity and mortality after kidney transplantation. Transplant international : official journal of the European society for. Organ Transplant. 2015;28(1):10-21.

25. Lentine $\mathrm{KL}$, Villines TC, Xiao H, Schnitzler MA, Brennan DC, Abbott KC, et al. Cardioprotective medication use after acute myocardial infarction in kidney transplant recipients. Transplantation. 2011;91(10):1120-6.

26. Gaston RS, Kasiske BL, Fieberg AM, Leduc R, Cosio FC, Gourishankar S, et al. Use of cardioprotective medications in kidney transplant recipients. Am J Transplant Off J Am Soc Transplant Am Soc Transplant Surg. 2009;9(8):1811-5.
27. Dauerman HL, Bates ER, Kontos MC, Li S, Garvey JL, Henry TD, Manoukian SV, Roe MT. Nationwide Analysis of Patients With ST-Segment-Elevation Myocardial Infarction Transferred for Primary Percutaneous Intervention: Findings From the American Heart Association Mission: Lifeline Program. Circ Cardiovasc Interv. 2015;8(5):e002450.

28. Malik AO, Abela O, Allenback G, Devabhaktuni S, Lui C, Singh A, et al. STsegment elevation myocardial infarction, systems of care. An urgent need for policies to co-ordinate care in order to decrease in-hospital mortality. Int J Cardiol. 2017

29. Patterson ME, Hernandez AF, Hammill BG, Fonarow GC, Peterson ED, Schulman KA, et al. Process of care performance measures and long-term outcomes in patients hospitalized with heart failure. Med Care. 2010;48(3): 210-6.
Ready to submit your research? Choose BMC and benefit from:

- fast, convenient online submission

- thorough peer review by experienced researchers in your field

- rapid publication on acceptance

- support for research data, including large and complex data types

- gold Open Access which fosters wider collaboration and increased citations

- maximum visibility for your research: over $100 \mathrm{M}$ website views per year

At $\mathrm{BMC}$, research is always in progress.

Learn more biomedcentral.com/submissions 